\title{
Background familiar versus perfil escolar do município: qual possui maior impacto no resultado educacional dos alunos brasileiros?
}

\author{
Juliana de Lucena Ruas Riani ${ }^{\star}$ \\ Eduardo Luiz Gonçalves Rios-Neto**
}

\begin{abstract}
Na trajetória escolar das pessoas, vários fatores podem influenciar seu sucesso, entre os quais se destacam aqueles relacionados ao ambiente familiar e a disponibilidade e qualidade da infra-estrutura da escola e seus professores. No Brasil, a maioria dos trabalhos demonstra a grande importância da família na educação de seus filhos, indicando a forte estratificação educacional. Porém, resta saber como a qualidade da escola e dos seus docentes pode diminuir essa estratificação. Esse artigo busca investigar os determinantes do resultado educacional nos níveis de ensino fundamental e médio no Brasil, considerando fatores relacionados ao background familiar e a estrutura escolar dos municípios. Essa análise é importante por examinar quais fatores do perfil escolar dos municípios podem diminuir a importância do ambiente familiar, no sentido de reduzir a estratificação educacional, ou seja, a relação entre a trajetória escolar do indivíduo e sua origem social.
\end{abstract}

Palavras-chave: Educação. Estratificação educacional.

\section{Introdução}

Na trajetória escolar das pessoas, vários fatores podem influenciar seu sucesso, entre os quais se destacam aqueles relacionados ao ambiente familiar e a disponibilidade e qualidade da infra-estrutura da escola e seus professores.

O impacto da família refere-se, principalmente, à sua influência sobre a demanda educacional. De acordo com Silva e Hasenbalg (2001), existem três dimensões importantes com relação à estrutura familiar que afetam o desempenho do aluno na escola: o capital econômico, ou seja, os recursos financeiros disponíveis para os gastos educacionais dos filhos; o capital cultural da família ou recursos educacionais, que podem propiciar um am- biente mais adequado ao aprendizado; e a estrutura dos arranjos familiares, que pode facilitar ou prejudicar a ação dos indivíduos dentro da estrutura social.

Já os fatores escolares estão relacionados à oferta escolar, em termos tanto da sua disponibilidade quanto da sua qualidade, e seus efeitos seriam de minimizar o impacto da família no resultado educacional do indivíduo.

O debate sobre o impacto da família e da escola no resultado educacional já está bem adiantado nos países desenvolvidos, mas longe de se chegar a um consenso. Um dos primeiros estudos a abordar essa questão foi o Relatório de Coleman (COLEMAN et al., 1966), que concluiu que nos Estados Unidos os fatores de background

\footnotetext{
* Superintendente de informações educacionais da Secretaria do Estado da Educação de Minas Gerais.

** Professor titular do curso de Demografia do Centro de Desenvolvimento e Planejamento Regional -Cedeplar/UFMG.
} 
familiar são mais importantes do que os escolares na determinação do desempenho educacional da criança. Esse trabalho deu subsídio a vários outros que estenderam a análise para outros indicadores educacionais (HANUSHEK, 1998 e 2002; KRUEGER, 1998 e 2000; LEE; BARRO, 1997). Esses estudos tanto confirmaram os achados de Coleman como discordaram. Grande parte da controvérsia é devida à utilização de diferentes metodologias e tratamento das variáveis.

Nos países em desenvolvimento, esse debate ainda é recente, mas a maioria concorda com o grande impacto dos fatores familiares, porém, os efeitos da escola e dos professores não podem ser desprezados (BUCHMANN; HANNUM, 2001). O maior impacto da qualidade da escola e dos professores nos países em desenvolvimento, quando comparados àqueles desenvolvidos, pode estar refletindo a maior variabilidade dos recursos escolares nos primeiros, bem como a maior vulnerabilidade das famílias.

No Brasil, muitos estudos sobre os determinantes educacionais têm enfocado principalmente o papel da família na educação dos filhos (SILVA; HASENBALG, 2001; FERNANDES, 2002; BARROS; LAM, 1996), mostrando que os fatores de background familiar, principalmente a educação dos pais, possuem grande influência no resultado educacional. Esse tipo de análise é importante para o entendimento da educação, sobretudo em termos da estratificação educacional, uma vez que demonstra que pais pobres e com nível educacional mais baixo geralmente transferem baixa escolaridade para os filhos.

Já os estudos que incluem, além dos fatores familiares, aqueles relacionados à escola e ao ambiente comunitário (BARROS et al. 2001; RIOS-NETO; CÉZAR; RIANI, 2001) mostram que, apesar do importante impacto da família, os fatores relacionados à escola e à comunidade também provocam grande efeito no resultado educacional. Essa análise também é relevante, pois, além de auxiliar na formulação de políticas públicas educacionais mais eficazes, possibilita verificar até que ponto os fatores escolares minimizam a influência da família no resultado educacional do indivíduo.

Assim, o objetivo desse artigo é investigar os determinantes do resultado educacional nos níveis de ensino fundamental e médio no Brasil, considerando fatores relacionados ao background familiar e a estrutura escolar dos municípios. Essa análise é importante por examinar quais fatores do perfil escolar dos municípios podem diminuir a importância do ambiente familiar, reduzindo, dessa forma, a estratificação educacional, ou seja, a relação entre a trajetória escolar do indivíduo e sua origem social.

Para tanto, utilizou-se como pano de fundo a abordagem da Função de Produção Educacional (FPE), que analisa como os diversos insumos do processo de educação podem afetar os resultados educacionais de um indivíduo, sendo relevante por guiar a escolha dos principais determinantes educacionais.

De acordo com essa abordagem, os insumos educacionais podem ser divididos em três conjuntos de fatores. O primeiro incorpora os fatores relacionados à família, que, como já mencionado, alteram a demanda por educação, como, por exemplo, os recursos, a estrutura e o nível socioeconômico familiar. O segundo agrupa aqueles associados à escola, como infra-estrutura, nível educacional dos professores, tamanho de classes e organização escolar. E, por fim, o terceiro engloba fatores relacionados à comunidade, como estoque de capital e recursos, os quais, juntamente com o anterior, alteram a oferta educacional. A FPE foi especificada utilizando a modelagem hierárquica, que proporciona uma melhor obtenção das estimativas para os parâmetros, já que lida com a quebra de alguns pressupostos dos modelos clássicos. ${ }^{1}$

Outra vantagem dos modelos hierárquicos, que será importante nesse artigo, refere-se à possibilidade de analisar a interação entre os fatores de background

\footnotetext{
1 Pressupostos dos erros independentes e identicamente distribuídos.
} 
familiar e as variáveis da rede escolar dos municípios. Pode-se observar, por exemplo, se a melhora na qualidade dos serviços educacionais ofertados em um município tem maior impacto nos filhos de mães menos escolarizadas do que naqueles cujas mães possuem maior escolaridade.

Como resultado educacional, considerou-se a probabilidade de o aluno estar cursando determinada série na idade correta, tanto no ensino fundamental quanto no médio. Através dessa probabilidade, tentou-se captar a eficiência e o rendimento do sistema escolar, que estão relacionados com a repetência e/ou entrada tardia no sistema de ensino. Segundo dados do Censo Demográfico de 2000, no Brasil, a distorção entre a idade e a série adequada cursada é bastante alta nos dois níveis de ensino. No caso do fundamental, $54 \%$ das matrículas correspondiam a alunos com idade superior à considerada adequada para a série. No nível médio o quadro é ainda pior, pois $66 \%$ dos alunos matriculados possuíam idade superior àquela considerada adequada.

\section{Aspectos metodológicos}

Da mesma forma como em alguns trabalhos anteriores (RIANI, 2007; HANUSHEK, 2002; KRUEGER, 1999), a Função de Produção Educacional (FPE) foi utilizada como ponto de partida para analisar o impacto de alguns insumos escolares no resultado educacional. A FPE foi estimada por meio de modelo logístico hierárquico de dois níveis, em que o primeiro nível considera o indivíduo e o segundo, o município.

Esse modelo pode ser descrito da seguinte forma: ${ }^{2}$

Nível 1:

$\ln \left(\frac{\pi_{i j}}{1-\pi_{i j}}\right)=\beta_{0 j}+\beta_{1 j} X_{1 i j}+e_{i j}$

Nível 2:

$\beta_{0 j}=\gamma_{00}+\gamma_{01} W_{j}+u_{0 j}$

$\beta_{1 j}=\gamma_{10}+\gamma_{11} W_{j}+u_{1 j}$
Em que:

$\pi_{\mathrm{ij}}$ é a probabilidade de sucesso para o indivíduo i;

$i=1,2, \ldots, n_{j}$ unidades de nível 1 , que nesse caso são os indivíduos;

$j=1,2, \ldots, J$ unidades de nível 2 , que são os municípios;

$\beta_{0 j}$ e $\beta_{1 j}$ os coeficientes do intercepto e da variável independente do nível 1 , assumidos aleatórios;

$\gamma_{00}$ e $\gamma_{10}$ são os parâmetros da parte fixa do modelo, comum a todos os indivíduos;

$e_{\mathrm{ij}}$ é o efeito aleatório associado ao nível 1, ou seja, a quantidade aleatória para o ith indivíduo na jth unidade;

$u_{0 j}$ e $u_{1 j}$ são os efeitos aleatórios do nível 2;

$\mathrm{X}_{1 \mathrm{ij}}$ é o vetor de variáveis independentes do nível 1;

$W_{\mathrm{j}}$ é o vetor de variáveis independentes medidas no nível 2.

Como pode ser visto nas equações anteriores, o intercepto e a inclinação não são os mesmos para todas as unidades de nível 2. A variação pode se dar pelo efeito de alguma variável explicativa de nível 2 e por componente aleatório.

Cabe ressaltar que, no Brasil, os trabaIhos clássicos que utilizam os modelos hierárquicos para a análise escolar consideram no primeiro nível o aluno e, no segundo, a escola (FLETCHER, 1998; ALBERNAZ et al., 2002; CÉSAR; SOARES, 2001; FERRÃO, et al., 2001; BARBOSA; FERNANDES, 2001). Esses estudos utilizam a base de dados do Sistema de Avaliação da Educação Básica - Saeb e estão voltados para o estudo dos fatores associados ao desempenho escolar dos alunos. A despeito da importância desse foco, já que os resultados do Saeb indicam que a qualidade do ensino é baixa, o interesse do presente artigo é complementar esses estudos, analisando outro grande problema do ensino brasileiro, que é a alta distorção idade/série, conseqüência de uma alta repetência e/ou entrada tardia na escola.

\footnotetext{
2 Para mais detalhes dos modelos hierárquicos, ver Bryk e Raudenbush (2002).
} 
Diferente dos trabalhos citados anteriormente, nesse artigo a unidade de nível 2 corresponde aos municípios. Dessa forma, os fatores de insumos escolares e de professores foram agrupados por município. Em outras palavras, os insumos escolares são representados por aqueles que caracterizam a rede escolar do município e o objetivo passa a ser a rede de ensino eficaz. Assim busca-se saber como o perfil da oferta escolar dos municípios determina o resultado educacional do estudante.

Os municípios brasileiros possuem um perfil escolar bastante heterogêneo: alguns possuem a maioria dos estabelecimentos com boa qualidade da infra-estrutura e dos recursos humanos escolares, bem como grande oferta em todos os níveis de ensino, enquanto outros têm uma rede escolar bastante precária, com baixa qualidade no que se refere à infra-estrutura e aos recursos humanos escolares, além de grande restrição de oferta - alguns nem sequer oferecem a segunda metade do ensino fundamental e o ensino médio. Dessa forma, é importante saber se a rede escolar do município faz diferença para o resultado educacional dos estudantes.

\section{Tratamento das variáveis e base de dados}

Considerou-se como resultado educacional a eficiência do aluno na escola captada pela probabilidade de o aluno freqüentar a escola na idade correta, que expressa o grau de repetência e a entrada tardia no sistema de ensino. Como no modelo logístico hierárquico, as variáveis dependentes são medidas no nível 1 , ou seja, o indivíduo. Essa probabilidade foi modelada utilizando as seguintes categorias como variável resposta: "1", para o aluno que esteja cursando a série adequada à sua idade; e "0", caso contrário. Como se pretende analisar os ensinos fundamental e médio, foram utilizadas duas amostras diferentes de acordo com a idade adequada de cursar cada nível de ensino. Dessa forma, para o fundamental, foram considerados os alunos de 7 a 14 anos e, para o ensino médio, aqueles de 15 a 17 anos de idade.
Conforme já mencionado, as variáveis independentes foram selecionadas tendo como pano de fundo a FPE. Como esse trabalho considera o aluno no primeiro nível do modelo hierárquico, as variáveis independentes nesse nível estão relacionadas aos atributos pessoais (idade, sexo, cor e situação de domicílio) e ao background familiar dos alunos.

A idade do aluno foi medida de forma contínua (anos completos de idade) e sua inclusão é importante, pois vários estudos demonstram que existe uma relação negativa entre a idade e a repetência, ou seja, quanto mais velha a criança maior a probabilidade de freqüentar séries abaixo da adequada para a sua idade.

O sexo também foi considerado para controlar as possíveis diferenças em relação ao gênero. Portanto, foi incluída uma variável categórica, sendo "1", para os homens, e "0", para as mulheres. Espera-se que o sinal dessa variável seja negativo, ou seja, que os homens tenham uma pior performance em relação às mulheres, já que a maioria dos estudos mostra que as mulheres jovens apresentam resultados educacionais superiores aos dos homens.

Outro fator de controle muito importante é a cor do indivíduo. A relevância dessa variável para o caso brasileiro é analisada em vários estudos de estratificação social (FERNADES, 2001; SILVA; HASENBALG, 2001), que encontraram um forte efeito da cor sobre as transições escolares. Os resultados mostram que os negros (cor preta ou parda) possuem desvantagem educacional em relação aos brancos, mesmo depois de se controlar por variáveis socioeconômicas. Tal fato pode estar refletindo fatores discriminatórios ou culturais. Dessa forma, a variável cor foi considerada nas regressões de forma categórica, sendo "1" para brancos e amarelos e "0" para pretos e pardos (ou negros).

A situação de residência do indivíduo, morador da zona rural ou urbana, foi outra variável controle, codificada da seguinte forma: "1", se a pessoa for moradora da área urbana; e "0", caso contrário. Essa variável tentou captar os diferenciais urbano/rural no desempenho do sistema escolar. 
Como o presente trabalho propõe analisar o impacto do background familiar versus o perfil escolar dos municípios, as variáveis relacionadas ao ambiente familiar são extremamente importantes. Tendo como base estudos anteriores sobre os determinantes educacionais, ${ }^{3}$ consideraram-se as seguintes variáveis de background familiar:

- escolaridade da mãe - foi medida em termos dos anos de estudo completo da mãe, variando de 0 a 16 anos de estudo. De acordo com Silva e Hasenbalg (2001), essa variável representa o "capital cultural" familiar, sendo que a hipótese é de que crianças pertencentes a famílias com baixo capital cultural (nesse caso mães com baixa escolaridade) apresentam pior desempenho na escola, com maiores chances de evasão e de repetência. Alguns estudos utilizam a educação do chefe ou dos pais separadamente, porém, a escolha da escolaridade da mãe deveu-se ao fato desta ser mais importante na determinação do resultado educacional dos filhos do que a do pai, como mostra vários trabalhos, entre os quais os de Lam e Barros (1995) e Rios-Neto, Cesar e Riani (2001);

- categoria de ocupação do chefe - foi utilizada a agregação de ocupação proposta por Silva (1973 e 1985), que busca uma homogeneização das categorias ocupacionais e leva em conta o nível educacional exigido para o exercício de cada ocupação, o tipo de especialização de suas funções e o nível de rendimento, estratificando-os em três níveis ocupacionais: nível superior e gerencial; nível médio; e nível manual. Para não perder informação das famílias cujos chefes não estão ocupados, criouse uma quarta categoria para os inativos, ou seja, os desempregados ou aposentados. Nas regressões, a categoria de referência foi a de nível manual. A categoria de ocupação do chefe é indicadora tanto do "capital econômico" quanto do "capital cultural" da família, já que expressa tanto o nível de rendimento de cada ocupação como o de instrução. Pode-se supor também que há uma correlação dessas variáveis com a educação paterna, uma vez que a maioria das famílias é chefiada por homens;

- chefia feminina - foi incluída como variável dicotômica, sendo "1" para os domicílios chefiados por mulher e "0", caso contrário. Segundo Silva e Hasenbalg (2001), essa variável está relacionada com o "capital social" e reflete o fato de a família ser quebrada ou não, já que a maioria das famílias chefiadas por mulheres é monoparental;

- família convivente - também foi medida de forma dicotômica, assumindo os seguintes valores: "1" para famílias que convivem com outras no mesmo domicílio e "0", caso contrário. Pode-se dizer que essa variável também reflete o "capital social", pois está relacionada com os aspectos da estrutura familiar, como, por exemplo, o caso de filhos de mães solteiras que moram com os avós. Ela também foi incluída como forma de controlar o fato de outras pessoas adultas pertencentes a outra família, mas que convivem no mesmo domicílio, interferirem na educação do indivíduo, seja por possuir maior nível educacional, seja por ter maior renda.

Cabe ressaltar que algumas variáveis de background familiar, reconhecidamente importantes para o desempenho escolar do indivíduo, como é o caso da renda familiar per capita e do número de filhos na família, foram omitidas na análise. Optou-se por essa omissão por elas estarem sujeitas a possíveis vieses de simultaneidade, o que

\footnotetext{
${ }^{3}$ Ver: Riani (2005), Lam e Barros (1995), Rios-Neto, César e Riani (2001) e Barros et al. (2001).
} 
requer uma discussão teórica mais aprofundada. Somado a isso, a educação materna e a categoria de ocupação do chefe podem possuir uma forte correlação com essas variáveis.

As variáveis explicativas incluídas no segundo nível tiveram a finalidade de captar as condições de oferta escolar do município e as características municipais que possam influenciar o desempenho escolar dos indivíduos. Os fatores da rede escolar do município estão relacionados à qualidade, disponibilidade e distribuição dos serviços educacionais.

Para medir a qualidade dos serviços educacionais, foram considerados dois conjuntos de insumos, um ligado à qualidade dos recursos humanos e outro à qualidade da infra-estrutura das escolas. Com relação ao primeiro, foram utilizadas três variáveis: média de horas-aula diária; média de alunos por turma; e percentual de docentes com curso superior. Para a qualidade da infraestrutura das escolas, foi feita uma análise fatorial por componentes principais do percentual de alunos no município beneficiados por estabelecimentos com quadras de esporte, bibliotecas, laboratório de informática e laboratório de ciências. Esse índice foi chamado de fator de infra-estrutura.

Com relação à disponibilidade e distribuição dos serviços educacionais, foram consideradas a restrição de oferta, medida em termos da razão entre o número de professores em cada nível de ensino e a população em idade adequada de cursar determinado nível de ensino, a distribuição das matrículas segundo tamanho dos estabelecimentos, ${ }^{4}$ a distribuição das matrículas segundo dependência administrativa ${ }^{5}$ e a organização do ensino em ciclos, ${ }^{6}$ captada pelo número de matrículas em escolas com ciclos sobre o total de matrículas do município.
Para os fatores comunitários, foram incluídas a educação média da população adulta, considerada como capital social do município, e variáveis categóricas controlando o tamanho da população. Tanto as variáveis referentes ao perfil escolar quanto as comunitárias foram medidas no âmbito do município (nível 2).

Todas as informações foram retiradas do Censo Demográfico de 2000 (IBGE) e do Censo Escolar de 2000 (Inep). Da primeira base, foram extraídos os dados sobre o indivíduo e sua família e, da segunda, aqueles relacionados à escola.

\section{Determinantes da probabilidade de cursar a escola na idade correta}

Para essa análise, foram estimados dois modelos de regressão. O modelo 1 é o nãocondicional, ou seja, não possui covariável de nível 2. No modelo 2 foram incluídas as covariáveis de nível 2 para determinar os coeficientes aleatórios do intercepto e da educação materna.

A opção de considerar a educação materna como tendo efeito aleatório baseou-se no artigo de Rios-Neto, César e Riani (2001), que testa o efeito aleatório de algumas variáveis do nível micro e cujos resultados apontam para uma variância aleatória do coeficiente ligado à educação da mãe. Assim, para os modelos de regressões, tanto o intercepto quanto a inclinação não são os mesmos para os municípios. A vantagem de considerar que há variação no coeficiente da educação materna é a possibilidade de se analisar sua interação com as variáveis independentes do nível 2 na probabilidade de cursar a escola na idade adequada. Dessa forma, além de avaliar a importância da educação materna, verificou-se até que ponto seu efeito pode ser diminuído pela melhora na rede escolar dos municípios.

\footnotetext{
${ }^{4}$ Foram criadas três categorias para o tamanho de estabelecimentos em termos do número de alunos: proporção de estabelecimentos com 50 a 200 matrículas; proporção de estabelecimentos com 201 a 1.000 matrículas; e proporção de estabelecimentos com mais de 1.000 matrículas.

5 Para discriminar a distribuição das matrículas do município segundo a dependência administrativa, foram consideradas a porcentagem de matrículas públicas no município e a porcentagem de matrículas municipais entre as públicas. Optouse por discriminar apenas as escolas municipais entre as públicas porque as federais são em número muito pequeno, principalmente no caso do ensino fundamental.

6 Forma de organização que distribui os anos de escolaridade em grupos.
} 
Com a estimação do modelo nãocondicional, é possível obter a repartição da variância entre os diferentes níveis. Somado a isso, com a comparação dos modelos 1 e 2, pode-se verificar a contribuição das variáveis contextuais para a redução da variabilidade não-condicional do intercepto e da inclinação. ${ }^{7}$

Os resultados das regressões para os ensinos fundamental e médio encontramse nas Tabelas 1 e 2. A análise do efeito aleatório do modelo 1 para os dois níveis de ensino mostra que é aceitável a hipótese de considerar o intercepto e a educação materna como tendo efeitos aleatórios, já que eles foram significativos, ressaltando-se que, para a educação materna, o componente da variância é pequeno. Comparando-se os dois níveis de ensino, percebe-se que o efeito aleatório é maior para o ensino médio do que para o fundamental, no que se refere tanto ao intercepto quanto à educação materna. Quando todas as variáveis de nível 2 são incluídas (modelo 2), a variabilidade do intercepto é explicada em mais de $80 \%$ nos dois níveis de ensino, enquanto a variabilidade do coeficiente da educação materna é explicada mais no nível médio $(74,44 \%)$ do que no fundamental $(48,28 \%)$.

Após a análise do efeito aleatório, considera-se o resultado do efeito fixo. Levando-se em conta primeiramente as variáveis referentes aos atributos individuais, que tiveram a principal função de controle nas regressões, os resultados coincidem com o esperado para as duas amostras: impacto negativo, na probabilidade de cursar a escola na idade correta, para a idade e alunos do sexo masculino, e positivo, para alunos situados em áreas urbanas e de cor branca ou amarela.

Cabe destacar que o impacto negativo para alunos do sexo masculino é bastante significativo, principalmente para o ensino médio, o que sugere estudos mais aprofundados sobre os fatores que levam homens a atrasarem seus estudos mais do que as mulheres.

Da mesma forma, destaca-se o expressivo impacto para a situação de domicílio do aluno, o que pode estar relacionado com a estrutura do mercado de trabalho diferenciada entre os setores rural/urbano.

Os resultados mostram que as variáveis de background familiar possuem significativa relação com a probabilidade de o aluno cursar a escola na idade correta, sugerindo uma estratificação educacional. Os principais resultados são:

- forte impacto positivo da educação materna, o que corrobora estudos anteriores. Em outras palavras, filhos de mães mais escolarizadas possuem menor distorção idade/ série;

- impacto negativo para domicílios chefiados por mulheres. Como a maior parte das famílias chefiadas por mulheres no Brasil é monoparental e, por sua vez, essas mulheres chefes estão na sua maioria no mercado de trabalho, tal fato pode estar relacionado com a perda de tempo no auxílio às atividades escolares dos seus filhos;

- a probabilidade de o aluno cursar a escola na idade correta aumenta com o status da categoria de ocupação do chefe da família;

- família convivente possui um efeito pequeno, não sendo significativo para o ensino fundamental e negativo para o médio.

Comparando os efeitos diferenciados nos ensinos fundamental e médio, observase que o impacto tanto dos atributos individuais (exceto idade) quanto do background familiar é bem maior para o ensino médio.

\footnotetext{
7 Para essa analise é calculada a proporção da variância explicada.

$\%$ da variância explicada $=\frac{\hat{\sigma}_{00(\text { (não-condicional })}-\hat{\sigma}_{00(\text { condiciona })}}{\hat{\sigma}_{00(\text { não-condicional })}}$
} 
TABELA 1

Resultado da regressão para a probabilidade de freqüentar a escola na idade correta - indivíduos de 7 a 14 anos que freqüentam a escola

Brasil - 2000

\begin{tabular}{|c|c|c|c|c|}
\hline \multirow[t]{2}{*}{ Variáveis independentes } & \multicolumn{2}{|c|}{ Modelo 1} & \multicolumn{2}{|c|}{ Modelo 2} \\
\hline & Coeficiente & Sig. & Coeficiente & Sig. \\
\hline \multicolumn{5}{|l|}{ Efeito fixo } \\
\hline Intercepto & $-0,604$ & 0,000 & $-4,520$ & 0,000 \\
\hline Razão professor/pop. 7 a 14 anos & & & $-0,800$ & 0,029 \\
\hline Proporção de matrículas em escolas com ciclo & & & 0,179 & 0,000 \\
\hline Proporção de matrículas públicas & & & 1,301 & 0,000 \\
\hline Proporção de matrículas municipais entre as públicas & & & $-0,173$ & 0,000 \\
\hline Proporção de estabelecimentos com 50 a 200 matrículas & & & $-0,139$ & 0,000 \\
\hline Proporção de estabelecimentos com 201 a 1.000 matrículas & & & $-0,062$ & 0,027 \\
\hline Proporção de estabelecimentos com mais de 1.000 matrículas & & & 0,164 & 0,118 \\
\hline Educação média da população adulta & & & 0,261 & 0,000 \\
\hline População até 4.999 & & & 0,392 & 0,000 \\
\hline População entre 5.000 e 9.999 & & & 0,381 & 0,000 \\
\hline População entre 10.000 e 19.999 & & & 0,338 & 0,000 \\
\hline População entre 20.000 e 49.999 & & & 0,269 & 0,000 \\
\hline População entre 50.000 e 99.999 & & & 0,218 & 0,000 \\
\hline População entre 100.000 e 199.999 & & & 0,135 & 0,003 \\
\hline Horas-aula diárias & & & 0,314 & 0,000 \\
\hline Alunos por turma & & & $-0,007$ & 0,000 \\
\hline Proporção de professores com curso superior & & & 0,563 & 0,000 \\
\hline Fator de infra-estrutura & & & 0,135 & 0,000 \\
\hline Idade & $-0,231$ & 0,000 & $-0,231$ & 0,000 \\
\hline Situação de domicílio; $1=$ urbano e $0=$ rural & 0,313 & 0,000 & 0,313 & 0,000 \\
\hline Cor; $1=$ branco e amarelo e $0=$ preto e pardo & 0,181 & 0,000 & 0,181 & 0,000 \\
\hline Sexo; $1=$ homem e $0=$ mulher & $-0,226$ & 0,000 & $-0,226$ & 0,000 \\
\hline Educação da mãe & 0,091 & 0,000 & 0,210 & 0,000 \\
\hline Razão professor/pop. 7 a 14 anos & & & 0,292 & 0,000 \\
\hline Proporção de matrículas em escolas com ciclo & & & 0,006 & 0,030 \\
\hline Proporção de matrículas públicas & & & $-0,166$ & 0,000 \\
\hline Proporção de matrículas municipais entre as públicas & & & 0,014 & 0,001 \\
\hline Proporção de estabelecimentos com 50 a 200 matrículas & & & $-0,002$ & 0,634 \\
\hline Proporção de estabelecimentos com 201 a 1.000 matrículas & & & 0,006 & 0,193 \\
\hline Proporção de estabelecimentos com mais de 1.000 matrículas & & & 0,032 & 0,034 \\
\hline Educação média da população adulta & & & $-0,014$ & 0,000 \\
\hline População até 4.999 & & & $-0,041$ & 0,000 \\
\hline População entre 5.000 e 9.999 & & & $-0,033$ & 0,000 \\
\hline População entre 10.000 e 19.999 & & & $-0,027$ & 0,000 \\
\hline População entre 20.000 e 49.999 & & & $-0,020$ & 0,000 \\
\hline População entre 50.000 e 99.999 & & & $-0,012$ & 0,014 \\
\hline População entre 100.000 e 199.999 & & & $-0,005$ & 0,303 \\
\hline Horas-aula diárias & & & 0,024 & 0,000 \\
\hline Alunos por turma & & & 0,001 & 0,000 \\
\hline Proporção de professores com curso superior & & & $-0,062$ & 0,000 \\
\hline Fator de infra-estrutura & & & $-0,008$ & 0,000 \\
\hline Domicílio chefiado por mulher & $-0,139$ & 0,000 & $-0,139$ & 0,000 \\
\hline Família convivente & 0,009 & 0,240 & 0,008 & 0,260 \\
\hline Categoria de ocupação do chefe nível superior & 0,127 & 0,000 & 0,128 & 0,000 \\
\hline Categoria de ocupação do chefe nível médio & 0,088 & 0,000 & 0,089 & 0,000 \\
\hline Chefe não ocupado & $-0,063$ & 0,000 & $-0,062$ & 0,000 \\
\hline \multicolumn{5}{|l|}{ Efeito aleatório } \\
\hline Coeficiente & 0,580 & 0,000 & 0,107 & 0,000 \\
\hline Educação da mãe & 0,003 & 0,000 & 0,001 & 0,000 \\
\hline \% da variância explicada - intercepto & & & 81,63 & \\
\hline \% da variância explicada - educação materna & & & 48,28 & \\
\hline
\end{tabular}

Fonte: IBGE. Censo Demográfico 2000. Inep. Censo Escolar 2000. 
TABELA 2

Resultado da regressão para a probabilidade de freqüentar a escola na idade correta - indivíduos de 15 a 17 anos de idade que freqüentam a escola

Brasil - 2000

\begin{tabular}{|c|c|c|c|c|}
\hline \multirow[t]{2}{*}{ Variáveis independentes } & \multicolumn{2}{|c|}{ Modelo 1} & \multicolumn{2}{|c|}{ Modelo 2} \\
\hline & Coeficiente & Sig. & Coeficiente & Sig. \\
\hline \multicolumn{5}{|l|}{ Efeito fixo } \\
\hline Intercepto & $-1,889$ & 0,000 & $-6,634$ & 0,000 \\
\hline Razão professor/pop. 15 a 17 anos & & & 6,539 & 0,000 \\
\hline Proporção de estabelecimentos com 50 a 200 matrículas & & & 0,164 & 0,018 \\
\hline Proporção de estabelecimentos com 201 a 1.000 matrículas & & & 0,315 & 0,000 \\
\hline Proporção de estabelecimentos com mais de 1.000 matrículas & & & 0,208 & 0,051 \\
\hline Proporção de matrículas públicas & & & 0,659 & 0,000 \\
\hline Proporção de matrículas municipais entre as públicas & & & $-0,327$ & 0,000 \\
\hline Educação média da população adulta & & & 0,620 & 0,000 \\
\hline População até 4.999 & & & 1,316 & 0,000 \\
\hline População entre 5.000 e 9.999 & & & 1,172 & 0,000 \\
\hline População entre 10.000 e 19.999 & & & 0,978 & 0,000 \\
\hline População entre 20.000 e 49.999 & & & 0,763 & 0,000 \\
\hline População entre 50.000 e 99.999 & & & 0,502 & 0,000 \\
\hline População entre 100.000 e 199.999 & & & 0,358 & 0,000 \\
\hline Fator de infra-estrutura & & & 0,304 & 0,000 \\
\hline Horas-aula diárias & & & $-0,002$ & 0,948 \\
\hline Alunos por turma & & & $-0,010$ & 0,000 \\
\hline Proporção de professores com curso superior & & & 0,334 & 0,000 \\
\hline Idade & $-0,098$ & 0,000 & $-0,098$ & 0,000 \\
\hline Situação de domicílio; $1=$ urbano e $0=$ rural & 0,521 & 0,000 & 0,525 & 0,000 \\
\hline Cor; 1 =branco e amarelo e $0=$ preto e pardo & 0,396 & 0,000 & 0,396 & 0,000 \\
\hline Sexo; 1 =homem e $0=$ mulher & $-0,546$ & 0,000 & $-0,547$ & 0,000 \\
\hline Educação da mãe & 0,173 & 0,000 & 0,330 & 0,000 \\
\hline Razão professor/pop. 15 a 17 anos & & & $-0,171$ & 0,029 \\
\hline Proporção de estabelecimentos com 50 a 200 matrículas & & & $-0,019$ & 0,045 \\
\hline Proporção de estabelecimentos com 201 a 1.000 matrículas & & & $-0,028$ & 0,003 \\
\hline Proporção de estabelecimentos com mais de 1.000 matrículas & & & $-0,022$ & 0,099 \\
\hline Proporção de matrículas públicas & & & $-0,065$ & 0,000 \\
\hline Proporção de matrículas municipais entre as públicas & & & 0,024 & 0,001 \\
\hline Educação média da população adulta & & & $-0,033$ & 0,000 \\
\hline População até 4.999 & & & $-0,075$ & 0,000 \\
\hline População entre 5.000 e 9.999 & & & $-0,063$ & 0,000 \\
\hline População entre 10.000 e 19.999 & & & $-0,051$ & 0,000 \\
\hline População entre 20.000 e 49.999 & & & $-0,041$ & 0,000 \\
\hline População entre 50.000 e 99.999 & & & $-0,035$ & 0,000 \\
\hline População entre 100.000 e 199.999 & & & $-0,026$ & 0,000 \\
\hline Fator de infra-estrutura & & & $-0,016$ & 0,000 \\
\hline Horas-aula diárias & & & 0,028 & 0,000 \\
\hline Alunos por turma & & & 0,001 & 0,000 \\
\hline Proporção de professores com curso superior & & & $-0,032$ & 0,000 \\
\hline Domicílio chefiado por mulher & $-0,319$ & 0,000 & $-0,319$ & 0,000 \\
\hline Família convivente & $-0,057$ & 0,017 & $-0,057$ & 0,017 \\
\hline Categoria de ocupação do chefe nível superior & 0,337 & 0,000 & 0,336 & 0,000 \\
\hline Categoria de ocupação do chefe nível médio & 0,273 & 0,000 & 0,272 & 0,000 \\
\hline Chefe não ocupado & 0,019 & 0,008 & 0,018 & 0,012 \\
\hline \multicolumn{5}{|l|}{ Efeito aleatório } \\
\hline Coeficiente & 1,615 & 0,000 & 0,278 & 0,000 \\
\hline Educação da mãe & 0,005 & 0,000 & 0,001 & 0,000 \\
\hline \% da variância explicada - intercepto & & & 82,79 & \\
\hline \% da variância explicada - educação materna & & & 74,44 & \\
\hline
\end{tabular}

Fonte: IBGE. Censo Demográfico 2000. Inep. Censo Escolar 2000. 
Para as variáveis de nível 2 , são feitas duas análises: uma referente ao impacto direto no intercepto; e outra sobre o efeito substituição entre educação da mãe e as variáveis de nível 2. Na primeira análise, detecta-se o efeito das variáveis contextuais na probabilidade média de freqüentar a escola na idade correta. Na segunda, é possível perceber até que ponto o efeito da educação materna pode ser minimizado pelos fatores municipais.

O impacto direto dos fatores da rede escolar do município mostrou-se importante na probabilidade de cursar a escola na série adequada, para os dois níveis de ensino. Para melhor visualizar o efeito desses fatores, os Gráficos 1 e 2 apresentam o valor predito segundo simulações de mudanças nas variáveis de rede escolar, utilizando os coeficientes do modelo 2. Considerou-se a variação da média mais e menos o desvio padrão de cada variável.
Para o ensino fundamental, percebe-se que as variáveis relacionadas à qualidade dos serviços educacionais são os fatores com maior impacto. Entre estas, destacam-se o grande efeito da proporção de professores com curso superior - variável de qualidade dos recursos humanos - e o fator de infra-estrutura - medida proxy da qualidade da infra-estrutura média das escolas do município. Com relação às outras variáveis da rede escolar do município, os principais resultados no ensino fundamental são: pequeno impacto das variáveis de nucleação; efeito negativo para a porcentagem de matrículas municipais entre as públicas, sendo possível inferir que a municipalização do ensino pode não ser acompanhada de uma boa eficiência do ensino; e coeficiente negativo e significativo apenas a $3 \%$ para a razão professor/população de 7 a 14 anos.

No caso do ensino médio (Gráfico 2), entre os fatores relacionados ao perfil das

GRÁFICO 1

Impacto da variação dos fatores de estrutura escolar do município na probabilidade de freqüentar a escola na idade adequada - ensino fundamental

Brasil - 2000

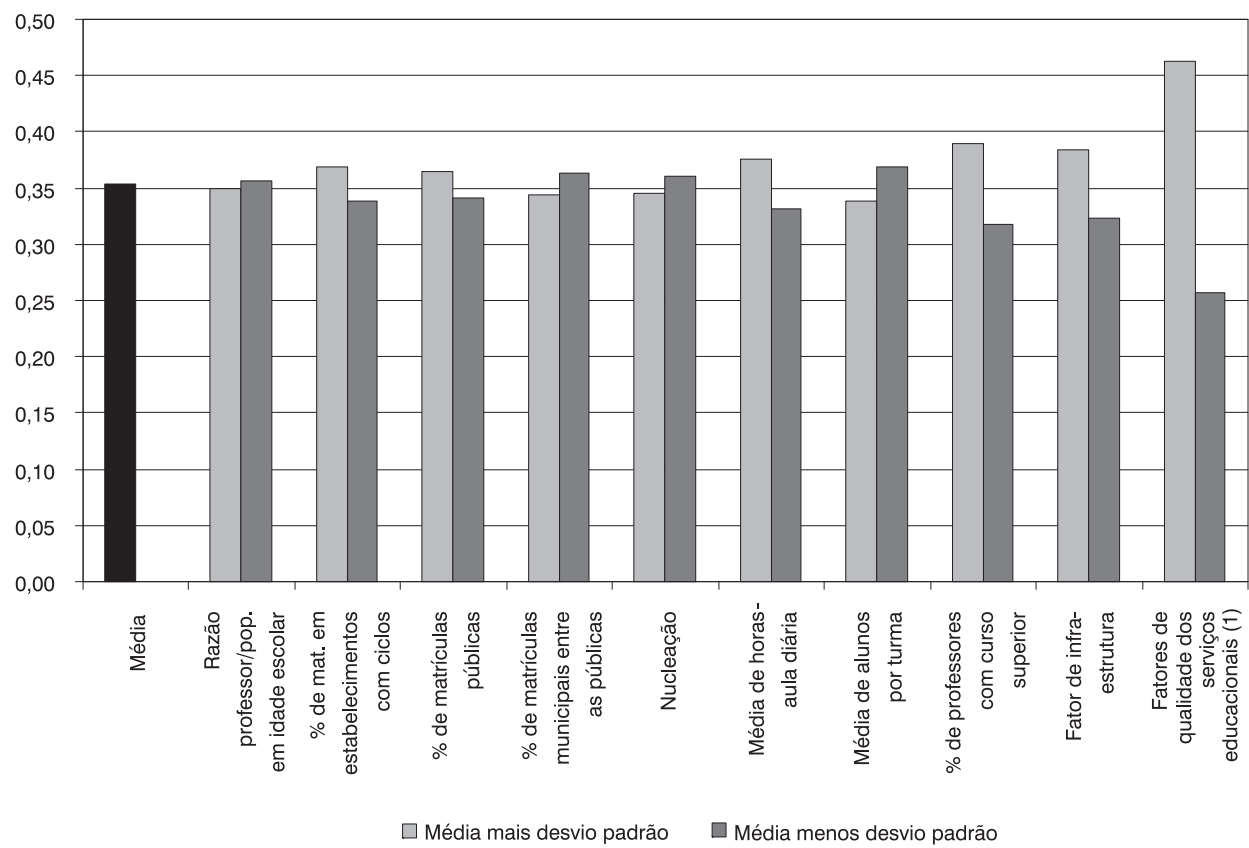

Fonte: IBGE. Censo Demográfico 2000. Inep. Censo Escolar 2000.

(1) Na simulação da melhoria nos fatores de qualidade dos serviços educacionais, para média de alunos por turma, considerouse a média menos o desvio padrão; e, para a piora, a média mais o desvio padrão. 
escolas do município, destaca-se o significativo impacto do fator de infra-estrutura. Verifica-se também que as variáveis de nucleação e restrição de oferta são mais importantes nesse nível de ensino do que no fundamental.

Cabe destacar que a melhora simultânea dos fatores de qualidade da rede escolar do município provoca um significativo aumento da freqüência na idade correta nos dois níveis de ensino, como pode ser visto nos Gráficos 1 e 2. Tal fato evidencia a importância de políticas públicas que estimulem a melhoria do perfil escolar dos municípios.

Os resultados das regressões mostram que tanto os fatores de background familiar quanto aqueles relacionados à estrutura escolar dos municípios são importantes na determinação da probabilidade de cursar a escola na idade correta, para os dois níveis de ensino. Para melhor comparar os efeitos de ambos fatores, a Tabela 3 contém as variações no valor predito decorrentes de mudanças desses fatores (considerou como variação a média mais e menos o desvio padrão de cada variável). Verifica-se que a educação materna realmente é o mais importante determinante da probabilidade de o aluno cursar a série na idade adequada. O aumento de um desvio padrão em relação à média na educação materna acresce em $24,25 \%$ a probabilidade de as crianças de 7 a 14 anos freqüentarem a escola na idade correta e em $81,30 \%$ para os jovens de 15 a 17 anos.

Observa-se, porém, que os fatores de rede escolar dos municípios apresentam impacto maior do que as demais variáveis de ambiente familiar e bastante significativo quando considera uma melhora simultânea nos fatores de qualidade dos serviços educacionais. Tal resultado traz implicações importantes para a política educacional, pois demonstra que, de certa forma, o contexto pode minimizar o papel da família sobre a eficiência do aluno. Cabe destacar que a maior variação no ensino médio em relação ao fundamental pode ser devida ao fato de o primeiro apresentar uma menor proporção

GRÁFICO 2

Impacto da variação dos fatores de estrutura escolar do município na probabilidade de freqüentar a escola na idade adequada - ensino médio

Brasil - 2000

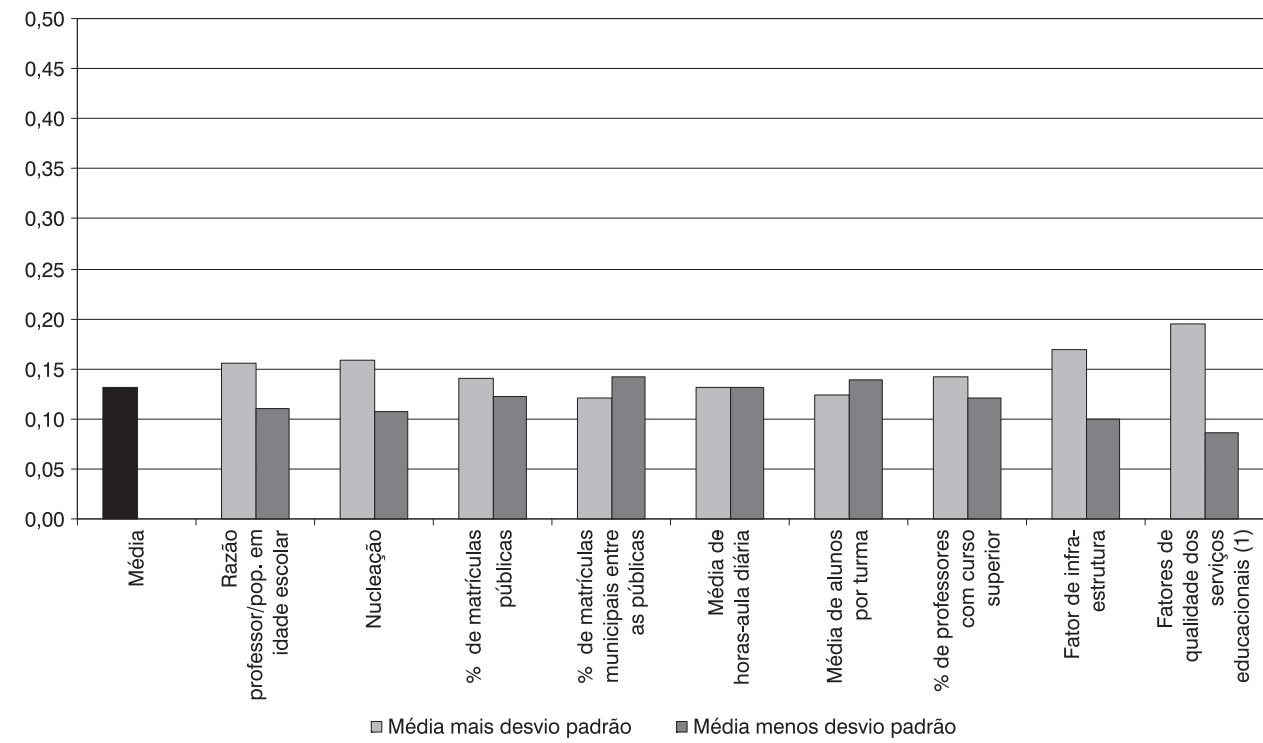

Fonte: IBGE. Censo Demográfico 2000. Inep. Censo Escolar 2000.

(1) Na simulação da melhoria nos fatores de qualidade dos serviços educacionais, para média de alunos por turma, considerou-se a média menos o desvio padrão; e, para a piora, a média mais o desvio padrão. 
de pessoas cursando a série adequada à sua idade, já que apenas $24 \%$ da amostra dos estudantes de 15 a 17 anos estava na série adequada, ao passo que para a amostra de 7 a 14 anos esse percentual era de $42 \%$.

Passando para a outra análise, referente ao efeito das variáveis agregadas no intercepto da educação materna, observa-se que, nos dois níveis de ensino, ocorre um efeito substituição entre essa variável e as relacionadas ao perfil escolar do município.

No ensino fundamental, esse efeito substituição é verificado para a porcentagem de professores com curso superior, alunos por turma e fator de infra-estrutura, ou seja, para a maioria dos fatores de qualidade escolar do município. Os coeficientes dessas variáveis são negativos e significativos no coeficiente da educação materna (para a média de alunos por turma o coeficiente é positivo). Em outras palavras, pode-se dizer que esses fatores são substitutos da educação materna. Assim, filhos de mães com baixa escolaridade são mais beneficiados pela melhora da qualidade da rede de ensino dos municípios do que aqueles cujas mães são mais escolarizadas, o que sugere que a melhoria dos fatores referentes ao perfil escolar do município tem um importante papel na diminuição das desigualdades educacionais entre os alunos de origens socioeconômicas diferentes.

Com o objetivo de melhor visualizar o efeito substituição mencionado, são apresentados, nos Gráficos 3 a 6, exercícios de simulação que mostram o impacto de uma variação simultânea da educação da mãe e dos fatores mais relevantes da rede escolar do município.

TABELA 3

Variações na probabilidade de freqüentar a escola na idade adequada, segundo variações nas variáveis de background familiar e rede escolar - ensinos fundamental e médio Brasil -2000

\begin{tabular}{|c|c|c|c|c|}
\hline \multirow[b]{2}{*}{ Variáveis independentes } & \multicolumn{2}{|c|}{ Ensino fundamental } & \multicolumn{2}{|c|}{ Ensino médio } \\
\hline & $\begin{array}{c}\text { Média mais } \\
\text { desvio } \\
\text { padrão }\end{array}$ & $\begin{array}{l}\text { Média menos } \\
\text { desvio } \\
\text { padrão }\end{array}$ & $\begin{array}{c}\text { Média mais } \\
\text { desvio } \\
\text { padrão }\end{array}$ & $\begin{array}{c}\text { Média menos } \\
\text { desvio } \\
\text { padrão }\end{array}$ \\
\hline \multicolumn{5}{|l|}{ Background familiar } \\
\hline Educação da mãe & 24,25 & $-21,85$ & 81,30 & $-48,10$ \\
\hline Domicílio chefiado por mulher & $-3,39$ & 3,44 & $-10,82$ & 11,91 \\
\hline Família convivente & 0,10 & $-0,10$ & $-0,59$ & 0,59 \\
\hline Categoria de ocupação do chefe nível superior & 2,16 & $-2,14$ & 8,47 & $-7,90$ \\
\hline Categoria de ocupação do chefe nível médio & 2,13 & $-2,11$ & 9,07 & $-8,42$ \\
\hline Chefe não ocupado & $-1,80$ & 1,81 & 0,74 & $-0,73$ \\
\hline \multicolumn{5}{|l|}{ Rede escolar } \\
\hline Razão professor/pop. em idade escolar & $-1,03$ & 1,04 & 18,31 & $-15,85$ \\
\hline \% de estabelecimentos com ciclo & 4,33 & $-4,25$ & - & - \\
\hline \% de matrículas públicas & 3,39 & $-3,34$ & 7,08 & $-6,68$ \\
\hline \% de matrículas municipais entre as públicas & $-2,78$ & 2,81 & $-7,42$ & 7,92 \\
\hline Nucleação & $-2,16$ & 2,18 & 21,34 & $-18,07$ \\
\hline Média de horas-aula diária & 6,39 & $-6,21$ & $-0,06$ & 0,06 \\
\hline Média de alunos por turma & $-4,25$ & 4,33 & $-5,75$ & 6,04 \\
\hline$\%$ de professores com curso superior & 10,42 & $-9,95$ & 8,71 & $-8,11$ \\
\hline Fator de infra-estrutura da rede escolar & 8,88 & $-8,54$ & 29,51 & $-23,60$ \\
\hline Fatores de qualidade dos serviços educacionais (1) & 31,06 & $-27,22$ & 48,10 & $-34,15$ \\
\hline
\end{tabular}

Fonte: IBGE. Censo Demográfico 2000. Inep. Censo Escolar 2000.

(1) Na simulação da melhoria nos fatores de qualidade dos serviços educacionais, para média de alunos por turma, considerou-se a média menos o desvio padrão; e, para a piora, a média mais o desvio padrão. 
No Gráfico 3, a visualização do efeito substituição entre a educação da mãe e a porcentagem de professores com curso superior é evidente. A linha do meio representa a educação da mãe na média, a superior quando a educação da mãe é três anos a mais do que a média e a inferior, três anos a menos. Considerando o início da curva, em que a porcentagem de professores com curso superior no município é igual a zero, o aumento da educação materna provoca um grande crescimento $(24,5 \%)$ na probabilidade de freqüentar a escola na idade adequada para as crianças de 7 a 14 anos. Por outro lado, uma diminuição reduz a probabilidade em $21,6 \%$. À medida que o percentual de professores com curso superior aumenta, o impacto da educação materna diminui. Dessa forma, quando o percentual de professores com curso superior é de $100 \%$, um aumento de três anos na média da educação materna eleva a probabilidade em $8,35 \%$, enquanto a diminuição de três anos reduz em $8,20 \%$ essa probabilidade. Pode-se dizer, portanto, que o impacto da educação da mãe na probabilidade de cursar a série na idade adequada no ensino fundamental decresce à medida que aumenta o porcentual de professores com curso superior no município.
Da mesma forma, os Gráficos 4 e 5 mostram o efeito substituição entre a educação materna e o número médio de alunos por turma e o fator de infra-estrutura do município, porém de maneira menos acentuada. Variações na educação materna possuem menor efeito em turmas pequenas, aumentando à medida que cresce o número de alunos por turma. No caso do fator de infra-estrutura, quanto maior a qualidade da infra-estrutura dos municípios, com aumento na porcentagem de matrículas em escolas com bibliotecas, quadras de esportes, laboratórios de informática e ciências, menor é o efeito da educação materna sobre a probabilidade de o filho freqüentar a escola na idade adequada.

O Gráfico 6 mostra a variação simultânea nos três fatores de qualidade da rede de ensino (infra-estrutura, porcentagem de professores com curso superior e média de alunos por turma). As escalas do eixo das abscissas representam a melhoria dos três fatores, correspondentes às escalas dos três gráficos anteriores. Assim, a escala 1 representa um município com nenhum professor com curso superior, média de 80 alunos por turma e fator de infra-estrutura escolar igual a $-1,3$. No outro extremo, a escala 8 representa todos os professores com curso

\section{GRÁFICO 3}

Impacto da variação da educação da mãe e do porcentual de professores com curso superior na probabilidade de freqüentar a escola na idade correta - ensino fundamental

Brasil - 2000

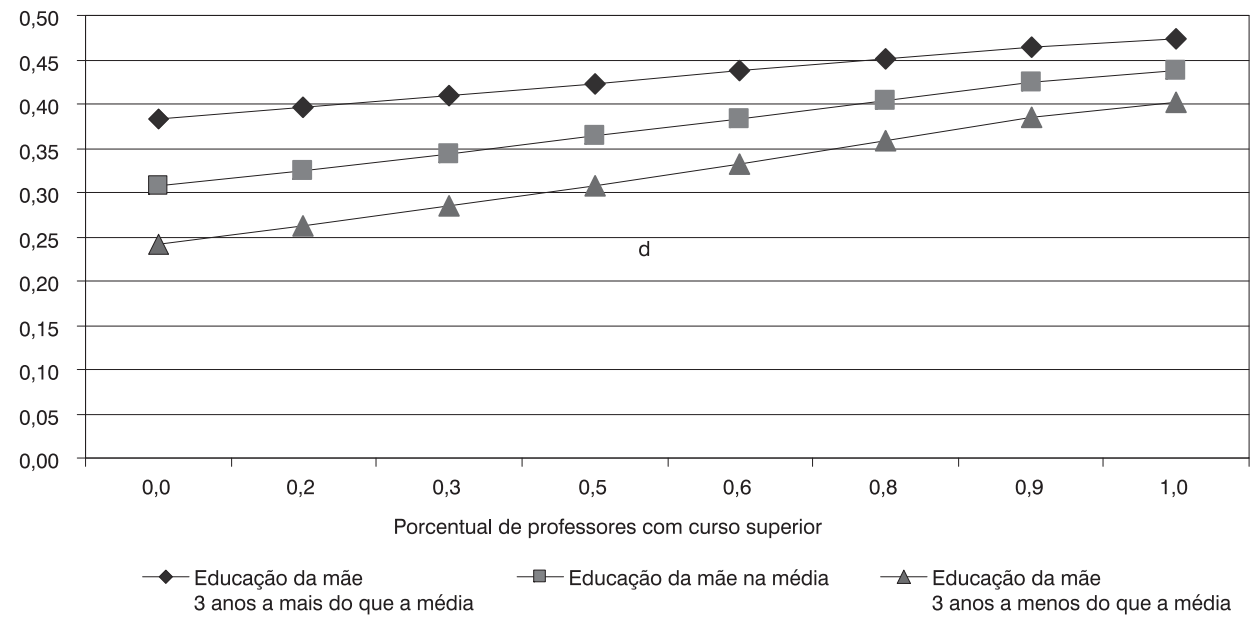

Fonte: IBGE. Censo Demográfico 2000; Inep. Censo Escolar 2000. 
GRÁFICO 4

Impacto da variação da educação da mãe e da média de alunos por turma na probabilidade de freqüentar a escola na idade correta - ensino fundamental

Brasil - 2000

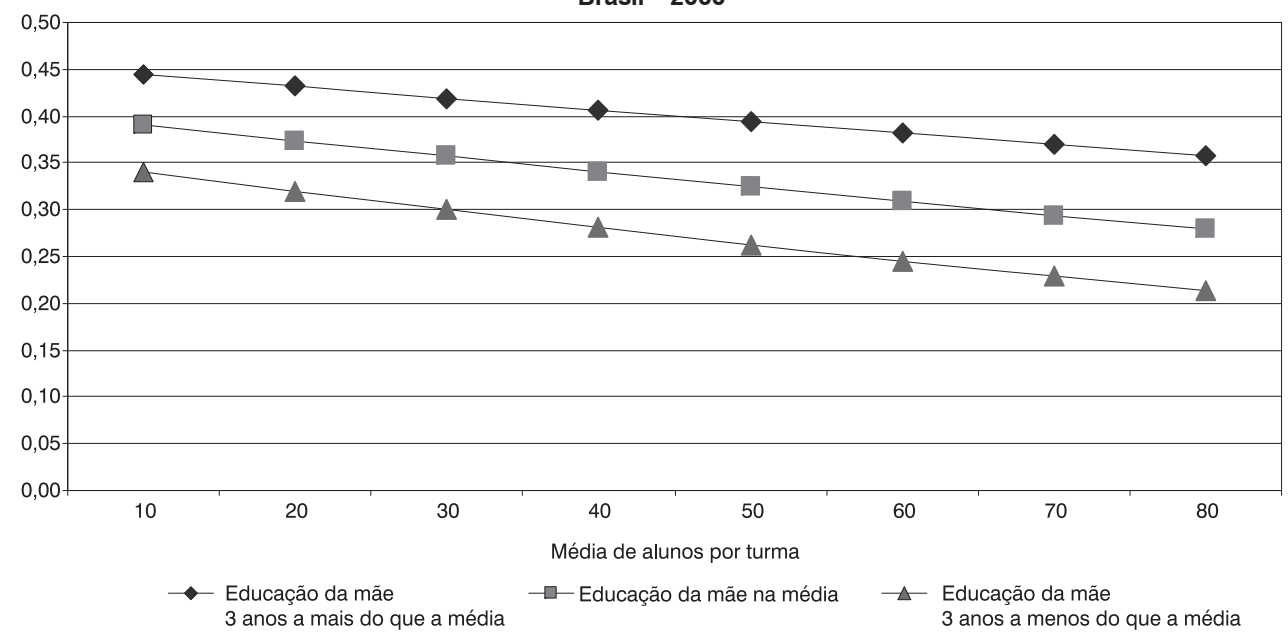

Fonte: IBGE. Censo Demográfico 2000; Inep. Censo Escolar 2000.

GRÁFICO 5

Impacto da variação da educação da mãe e do fator de infra-estrutura na probabilidade de freqüentar a escola na idade correta - ensino fundamental

Brasil - 2000

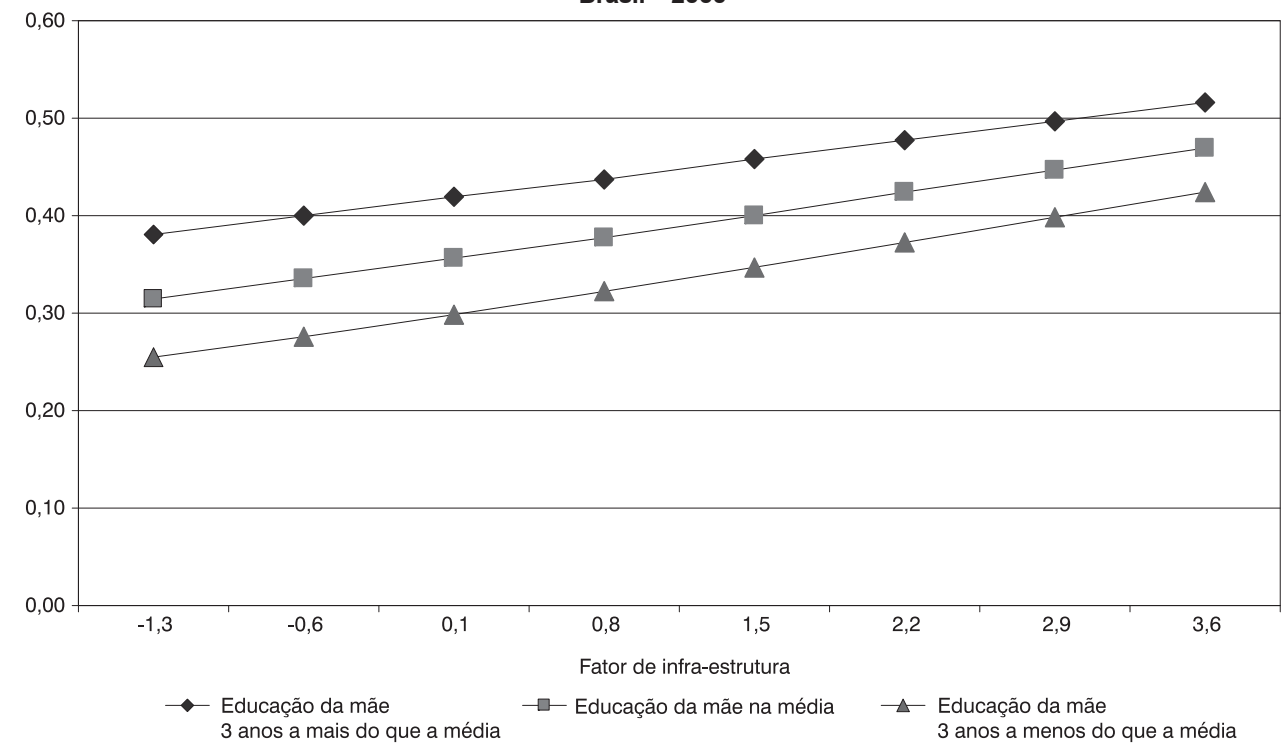

Fonte: IBGE. Censo Demográfico 2000; Inep. Censo Escolar 2000.

superior, média de alunos por turma igual a 10 e fator de infra-estrutura de 3,6.

Observa-se que uma variação simultânea nos três fatores de qualidade escolar possui grande efeito substituição com a educação materna. Em uma rede de ensino com alta qualidade de recursos humanos e de infra-estrutura, ou seja, salas pequenas, todos os professores com ensino superior e todas as escolas com quadras, bibliotecas 
GRÁFICO 6

Impacto da variação da educação da mãe e da qualidade da rede escolar do município na probabilidade de freqüentar a escola na idade correta - ensino fundamental

Brasil - 2000

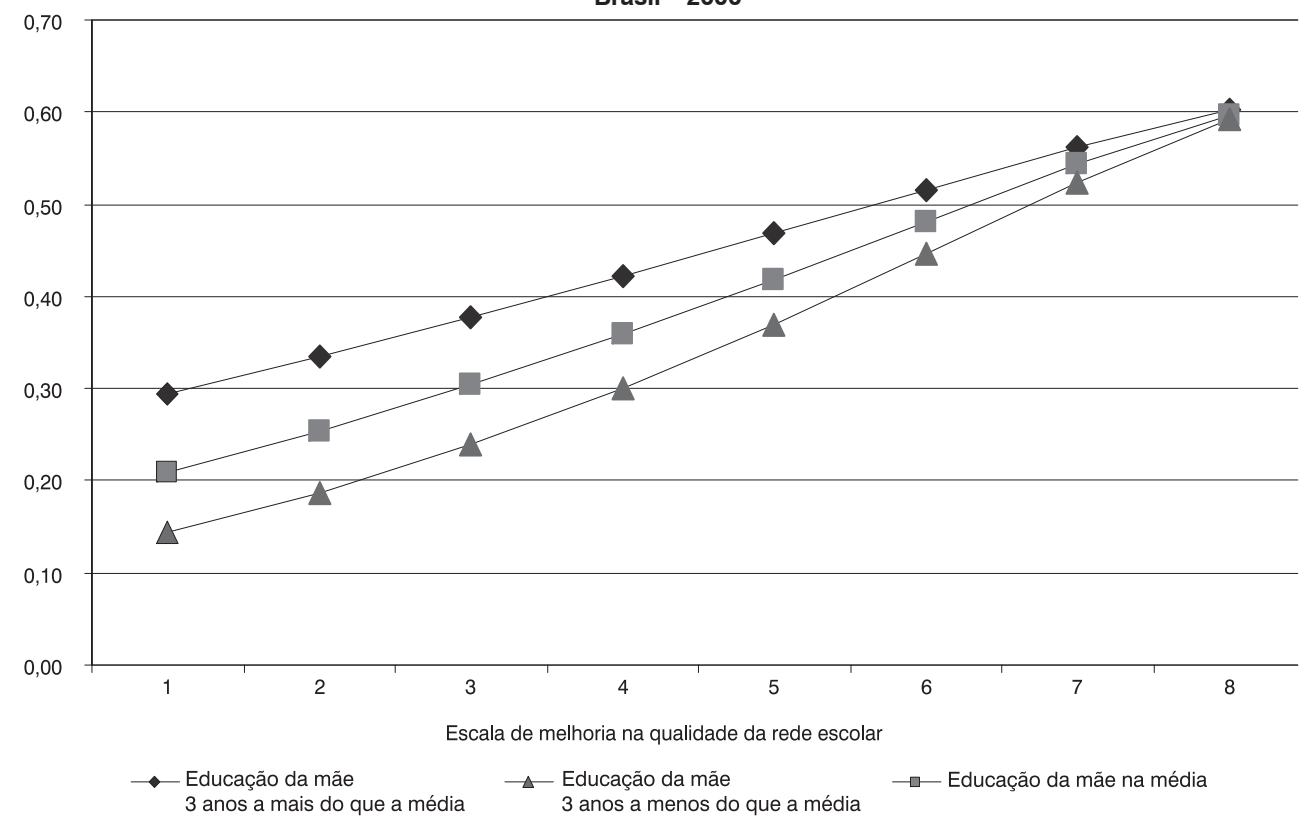

Fonte: IBGE. Censo Demográfico 2000; Inep. Censo Escolar 2000.

e laboratórios de ciências e informática, a probabilidade de o aluno freqüentar a escola na idade correta não difere quanto ao nível educacional da mãe. Nesse caso, tem-se uma situação em que as oportunidades educacionais não dependem da origem social do aluno, ou seja, uma sociedade com alta mobilidade social.

Para o ensino médio, o efeito substituição entre as varáveis relacionadas à rede escolar do município e a educação materna também ocorre e para as mesmas variáveis do caso anterior, porém, de forma bem mais sutil, não sendo possível visualizar graficamente esse efeito. Entretanto, quando se consideram municípios com $0 \%$ de professores com curso superior, um aumento de educação materna de três anos em relação à média eleva em $66,53 \%$ a probabilidade de os alunos de 15 a 17 anos cursarem a escola na idade correta. No outro extremo, considerando um valor de $100 \%$ para a porcentagem de professores com curso superior, um mesmo aumento na educação materna provoca um crescimento menor (50,39\%). O mesmo ocorre para o número de alunos por turma e para o fator de infraestrutura, ou seja, o impacto da educação materna é minimizado pela melhora desses fatores.

Com base no que foi exposto, pode-se dizer que a melhora do perfil escolar dos municípios possui dois efeitos: aumenta a probabilidade de o aluno freqüentar a escola na idade correta, para os dois níveis de ensino; e diminui a importância dos fatores relacionados ao ambiente familiar do aluno (no caso, educação da mãe), reduzindo a desigualdade intergeracional.

\section{Conclusão}

Esse artigo procurou estudar os determinantes da probabilidade de o aluno cursar a série na idade correta, nos ensinos fundamental e médio, utilizando a modelagem hierárquica. Os resultados evidenciaram a grande importância da educação materna 
nos indicadores educacionais, o que demonstra a alta estratificação educacional existente no Brasil, pois a trajetória escolar do aluno está bastante relacionada com a sua origem social. Em termos de políticas públicas, é importante conhecer os fatores que podem minimizar a importância da origem social do aluno, a fim de tornar o sistema mais igualitário. Nesse sentido, os resultados mostraram dois pontos importantes. Primeiro, verificou-se que os fatores relacionados à rede escolar dos municípios, principalmente os de qualidade dos recursos humanos e infra-estrutura dos serviços educacionais, aumentam a probabilidade média de freqüentar a escola na idade correta, ou seja, melhora os indicadores de eficiência do sistema de ensino.

Segundo, constatou-se a existência de um efeito substituição entre a educação

\section{Referências bibliográficas}

ALBERNAZ, A.; FERREIRA, F. H. G.; FRANCO, C. Qualidade e equidade no ensino fundamental brasileiro. Pesquisa e Planejamento Econômico, Rio de Janeiro, v.32, n.3, p.453-476, dez. 2002.

ANGRIST, J.; LAVY, V. Using maimonides rule to estimate the effect of class size on scholastic achievement. Quarterly Journal of Economics, v.114, n.2, p.533-75, May 1999.

ARMOR, D. J. School and family effects on black and white achievment: a reexamination of the USOE data. In: MOYNIHAN, D. P.; MOYNIHAN, D. P. (Eds.). On equality of educational opportunity: papers deriving from the Harvard University Faculty Seminar on the Coleman Report. New York: Vintage Books, 1972, p.168-229.

BARBOSA, M. E. F.; FERNANDES, C. A escola brasileira faz diferença? Uma investigação dos efeitos da escola na proficiência em matemática dos alunos da 4a série. In: FRANCO. C. (Org.). Avaliação, ciclos e promoção na educação. Porto Alegre: ArtMed, 2001, p.155-172.

BARBOSA, M. L. O. Efeitos da qualidade da escola sobre o desempenho dos materna e os fatores de qualidade da rede escolar dos municípios, de tal forma que uma melhora simultânea nesses fatores torna as oportunidades educacionais igualitárias para os alunos. Em outras palavras, pode-se dizer que o sucesso educacional, entendido aqui como a probabilidade de freqüentar a escola na idade correta, passa a não depender da origem social do aluno.

Em síntese, os resultados da análise hierárquica corroboram a hipótese de que a melhora da rede escolar dos municípios constitui um importante fator de diminuição da estratificação educacional, seja pelo seu efeito direto no aumento médio das probabilidades estudadas, seja por diminuir a importância dos fatores relacionados ao ambiente familiar do aluno (no caso, escolaridade da mãe), reduzindo a desigualdade intergeracional.

alunos. Washington, DC.: Latin American Studies Association, 2001. Mimeografado. Disponível em: <http://136.142.158.105/ Lasa2001/DeOliveiraBarbosaMaria.pdf>.

BARROS, R. P.; MENDONÇA, R. S. P.; SHOPE, J. A. Regional disparities in education within Brazil: the role of quality of education. Brasília: Ipea, 1993 (Texto para discussão, 311).

BARROS, R. P. et al. Determinantes do desempenho educacional do Brasil. Pesquisa e Planejamento Econômico, Rio de Janeiro, v.31, n.1. p.1-42, abr. 2001.

BARROS, R. P.; LAM, D. Income and education inequality and children's schooling attainment in Brazil. In: BIRDSALL, N.; SABOT, R.H. (Eds.). Opportunity forgone: education in Brazil. Washington, DC.: InterAmerican Development Bank, 1996.

BEHRMAN, J. R.; BIRDSALL, N. The quality of schooling: quality alone is misleading. The American Economic Review, v.73, n.5, p.928-946, Dec. 1983.

The quality of schooling: reply. The American Economic Review, v.75, n.5, p.1202-1205, Dec. 1985. 
BIDWELL, E.; KASARDA, D. Conceptualizing and measuring the effects of school and schooling. Journal of Education, v.88, n.4, p.401-430, 1980.

BIRDSALL, N.; SABOT, R. H. (Eds.). Opportunity forgone: education in Brazil. Washington, DC.: Inter-American Development Bank, 1996, p.7-47.

BLACK, S. E. Do better school matter? Parental valuation of elementary education. The Quarterly Journal of Economics, v.114, n.2, p.577-599, May 1999.

BRYK, A. S.; RAUDENBUSH, S. W. Hierarchical linear models: applications and data analysis methods. 2. ed. Newbury Park, California: Sage, 2002.

BUCHMANN, C., HANNUM, E. Education and stratification in developing countries: a review of theories and research. Annual Review of Sociology, v.27, p.77-102, Jan. 2001.

CARD, D.; KRUEGER, A. B. School resources and student outcomes: an overview of the literature and new evidence from North and South Carolina. Journal of Economic Perspectives, v.10, n.4, p.31-50, 1996.

CASTRO, M. H. G.; DAVANZO, A. M. Q. Situação da educação básica no Brasil. Brasília: Inep, 1999.

CÉSAR, C. C.; SOARES, J. F. Desigualdades acadêmicas induzidas pelo contexto escolar. Revista Brasileira de Estudos Populacionais, v.18, n.1/2, p.97-110, jan./ dez. 2001.

COLEMAN, J. S. et al. Equality of educational opportunity. Washington, DC: US Department of Health, Education \& Welfare, 1966.

COLEMAN, J. S. Social capital in the creation of human capital. In: LESSER, E. L. (Ed.). Knowledge and social capital: foundation and application. Boston: Butterworth Hewinemann, 2000, Cap.2, p.17-41.

EATON, P. J. The quality of schooling: comment. The American Economic Review, v.75, n.5, p.1.195-1.201, Dec. 1985.
FERNADES, D. C. Raça, origem socioeconômica e desigualdade educacional no Brasil, uma análise longitudinal. Trabalho apresentado na Reunião Anual da Associação Nacional de Pós-graduação e Pesquisa em Ciências Sociais (Anpocs). Outubro 2001.

FERRÃO, M. E. et al. O SAEB - Sistema Nacional de Avaliação da Educação Básica: objetivos, características e contribuições na investigação da escola eficaz. Revista Brasileira de Estudos de População, v.18, n.1/2, p.111-130, jan./dez. 2001.

FERREIRA, F. H. G.; BARROS, R. P. Education and income distribution in urban Brazil, 1976-1996. Cepal Review, n.71, p.41-61, Aug. 2000. Disponível em: <http://www.iets. inf.br/acervo/Artigos/Education\%20and\%20 income\%20distribution\%20in\%20urban\%20 Brazil,\%201976-1996.pdf>

FLETCHER, P. R. À procura do ensino eficaz. Rio de Janeiro: MEC, 1998.

FULLER, B.; CLARK, P. Raising school effects while ignoring culture? Local conditions and the influence of classroom tools, rule and pedagogy. Review of Educational Research, v.64, n.1, p.119-157, 1994.

GRUSKY, D. B.; DIPRETE, T. A. Recent trends in the process of stratification. Demography, v.27, n.4, p.617-637, Nov. 1990.

HANUSHEK, E. A. Evidence, politics, and the class size debate. In: MISHEL, L.; ROTHSTEIN, R. (Eds.). The class size debate. Washington, DC: Economic Policy Institute, 2002, p.3763.

Measuring investment in education.

Journal of Economics Perspectives, v.10, n.4, p.9-30, 1996.

Publicly provided education. In:

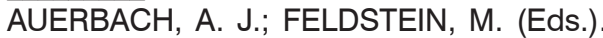
Handbook of public economics. Amsterdam: Elsevier, 2002, v.4, p. 2.045-2.141.

The evidence on class size. Rochester, NY: University of Rochester, W. Allen Wallis Institute of Political Economy, 1998 (Occasional Paper, 98-1).

HEALY, M. J. R. Multilevel data and their analysis. In: LEYLAND, A. H.; GOLDSTEIN, 
H. (Eds.). Multilevel modeling of health statistics. New York: Wiley, 2001, p.1-12.

HEYNEMAN, S. P.; LOXLEY, W. A. The effect of primary school quality on academic achievement across twenty-nine high and low - income countries. American Journal Sociology, v.88, n.6, p.1.162-1.194, May 1983.

HOX, J.J. Applied multilevel analysis. Amsterdam: TT-Publicities, 1995, Caps. 2 e 4.

. Multilevel modeling: when and why. In: BALDERJAHN, I.; MATHAR R.; SCHADER, M. (Eds.). Classification, data analysis, and data highways. New York: Springer Verlag, 1998, p.147-154.

KRUEGER, A. B. An economist's view of class size research. [Maryland]: Milkmen Institute, 2000 (Research paper).

. Economic consideration and class size. The Economic Journal, v.113, n.485, p.34-63, Feb. 2003.

Experimental estimates of education production functions. The Quarterly Journal of Economics, v.114, n.2, p.497532, May. 1999.

Reassessing the view that American schools are broken. Economic Research Bank of New York, v.4, n.1, p.2946, Mar. 1998.

LEE, J.; BARRO, R. J. Schooling quality in a cross section of countries. Cambridge: National Bureau of Economic Research, 1997 (Working paper, 6.198).

LEE, V. E.; BRIK, A. S. A multilevel model of the social distribution of high school achievement. Sociology of Education, v.62, n.3, p.172-192, July 1979 .

MARE, R. D.; CHEN, M. D. Further evidence on sibship size and educational stratification. American Sociological Review, v.51, n.3, p.403-412, June 1986.

MARE, R. D. Change and stability in educational stratification. American Sociological Review, v.46, n.1, p.72-87, 1981.
Social background composition and educational growth. Demography, v.16, n.1, p.55-71, Feb. 1979.

MARSHALL, G.; SWIFT, A.; ROBERTS, $S$. Against the odds? Social class and social justice in industrial societies. Oxford: Clarendon, 1997.

RICE, N. Binomial regression. In: LEYLAND, A. H.; GOLDSTEIN, H. (Eds.). Multilevel modeling of health statistics. New York: Wiley, 2001, p.27-43.

RIOS-NETO, E. L. G.; CÉSAR, C. C.; RIANI, J. L. R. Estratificação educacional e progressão escolar por série no Brasil. Pesquisa e Planejamento Econômico, Rio de Janeiro, v.32, n.3, p.395-415, dez. 2002.

RIOS-NETO, E. L. G.; RIANI, J. L. R. (Orgs.). Introdução à demografia da educação. Campinas: Abep, 2004.

SILVA, N. V. Atualização da escala socioeconômica de ocupação para 1980. Laboratório Nacional de Computação Científica, CNPq, 1985. Mimeografado.

Posição social das ocupações. Rio de Janeiro: IBGE, Centro de Informática, 1973. Mimeografado.

Posição social nas ocupações. Rio de Janeiro: IBGE, 1974. Mimeografado.

SILVA, N. V.; HASENBALG, C. Recursos familiares e transições educacionais. Versão preliminar apresentada no Workshop de Demografia da Educação, da Associação Brasileira de Estudos Populacionais - Abep. Salvador, junho 2001.

SOARES, J. F.; CÉSAR, C. C.; MANBRINI, J. Determinantes do desempenho dos alunos do ensino básico brasileiro: evidências do SAEB de 1997. In: FRANCO, C. (Org.). Avaliação, ciclos e promoção na educação. Porto Alegre: ArtMed, 2001, p.121-154.

SOARES, S. Os fatores que determinam o sucesso educacional. Pesquisa e Planejamento Econômico, Rio de Janeiro, v.32, n.3, p.385-394, dez. 2002.

TODD, P.E.; WOLPIN, K. I. On the specification and estimation of the production function 
for cognitive achievement. The Economic Journal, v.113, n.485, p.F3-F33, Feb. 2003.

WILLMS, J. D.; SOMERS, M. A. Schooling outcomes in Latin America. Report prepared for UNESCO, Aug. 1999, p.1-43.
WILLMS. J. D. Monitoring school performance for "standards-based reform". Evaluation and Research in Education, v.14, n.3/4, p.237-253, 2000.

\title{
Resumen
}

Background familiar versus perfil escolar del municipio: ¿Cuál posee mayor impacto en el resultado educacional de los alumnos brasileños?

En la trayectoria escolar de las personas, varios factores pueden influenciar su éxito, entre los cuales se destacan aquéllos relacionados con el ambiente familiar y la disponibilidad y calidad de la infraestructura de la escuela y sus profesores. En Brasil, la mayoría de los trabajos demuestra la gran importancia de la familia en la educación de sus hijos, indicando la fuerte estratificación educacional. Sin embargo, resta saber como la calidad de la escuela y de sus docentes puede disminuir esa estratificación. Este artículo busca investigar los determinantes del resultado educacional en los niveles de enseñanza fundamental y media en Brasil, considerando factores relacionados al background familiar y a la estructura escolar de los municipios. Este análisis es importante por examinar qué factores del perfil escolar de los municipios pueden disminuir la importancia del ambiente familiar, en el sentido de reducir la estratificación educacional, o sea, la relación entre la trayectoria escolar del individuo y su origen social.

Palabras-clave: Educación. Estratificación educacional.

\begin{abstract}
Family Background versus school profile of the municipality: which has greater impact on the academic performance of Brazilian students?

Many factors converge to define the success attained by individual students, including family background, school infrastructure and quality of teaching. Most studies in Brazil call attention to the great importance of the family in children's education, and indicate the country's considerable educational stratification. However, it is important to discuss how the quality of schools and teachers can reduce this stratification. This article describes a study on how to investigate the determinants of educational results in grade, middle and high schools in Brazil, considering both family background and local school structures. The analysis consists of an examination of what aspects of the profiles of local schools may help reduce the influence of family environment on educational stratification. The question, then, is how to lower the importance of the relationship between individual school experiences and social patterns among students.
\end{abstract}

Keywords: Education. Educational stratification.

Recebido para publicação em 13/01/2008. Aceito para publicação em 14/11/2008. 